\title{
La MIR, un monumento a las ingenierías ${ }^{1}$
}

Germán José Chacón Alvarado ${ }^{2}$

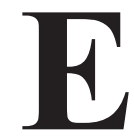

120 de febrero de 1986, en medio de una guerra entre polos opuestos y en medio de una lucha por la supremacía de algo desconocido, despegó desde el cosmódromo de Baikonour en Kasajistán, en la extinta Unión de Repúblicas Socialistas Soviéticas, un ambicioso proyecto: desarrollar una estación orbital capaz de alojar vida terrestre en el espacio exterior.

Para los nacidos en los años ochenta, la MIR es como una hermana que ha formado parte de nuestros sueños, buscándola en la inmensidad del cosmos, haciéndonos ver todo el talento que tiene el hombre, para que con el apoyo de obreros, artesanos, ingenieros y otros, pudiera poner en órbita una verdadera joya cosmonáutica, conformada, entre otros, por los módulos CORE, DOKING, KRJSTAL, KV4NT I y II, PRJRODA y SPEKTR.

Recordemos que MIR quiere decir PAZ, palabra que representa el mayor anhelo de la especie humana y esta estación espacial representó un sueño de hermandad, ya que en su impresionante estructura, con un peso de más de 135 toneladas y 40 metros de longitud, se realizaron más de 26000 experimentos, fue habitada por 104 cosmonautas de diferentes nacionalidades, dando paso 15 años después a lo que ha comenzado a ser la Estación Orbital Internacional, de la que Rusia es uno de los principales actores.

Hecha en la Tierra, la MIR cruzó el cielo, pasó por el fuego y cayó en el agua como si fuera una vieja leyenda griega. El 23 de marzo del 2001, a las 11:57 hora de Costa Rica, dejó de existir la MIR, joya de las ingenierías.

Publicado originalmente en Códice Da Vinci, año 3, número 8, mayo-agosto, 2001.

226 de octubre de 1983- 1 de marzo de 2017. 